\title{
EXPERIENCIAS CONSTRUCCIONISTAS CON ROBÓTICA EDUCATIVA EN EL CENTRO INTERNACIONAL DE TECNOLOGÍAS AVANZADAS.
}

\section{Resumen:}

La tecnología digital en relación a su utilización en el ámbito educativo tienen dos vertientes: la de información y la de construcción. Aunque el énfasis actual, debido a la percepción popular, se inclina a la parte informativa, este trabajo descubre una parte olvidada del potencial que ofrece la tecnología digital como medio de construcción, específicamente la robótica educativa, que por su carácter polivalente y multidisciplinario se sitúa como una herramienta de apoyo al aprendizaje novedosa y necesaria de conocer por las nuevas generaciones.

En este sentido, como ejemplo de buenas prácticas presentamos los talleres NXT de robótica del Centro Internacional de Tecnologías Avanzadas, un escenario construccionista de aprendizaje activo y lúdico, que les permite a los participantes mejorar su comprensión de la tecnología, potenciar habilidades y desarrollar la creatividad.

Palabras clave:

tecnología digital, construccionismo, robótica educativa, LEGO Mindstorms NXT.

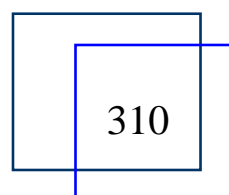

Kathia Pittí Patiño, Belén Curto Diego y Vidal Moreno Rodilla 


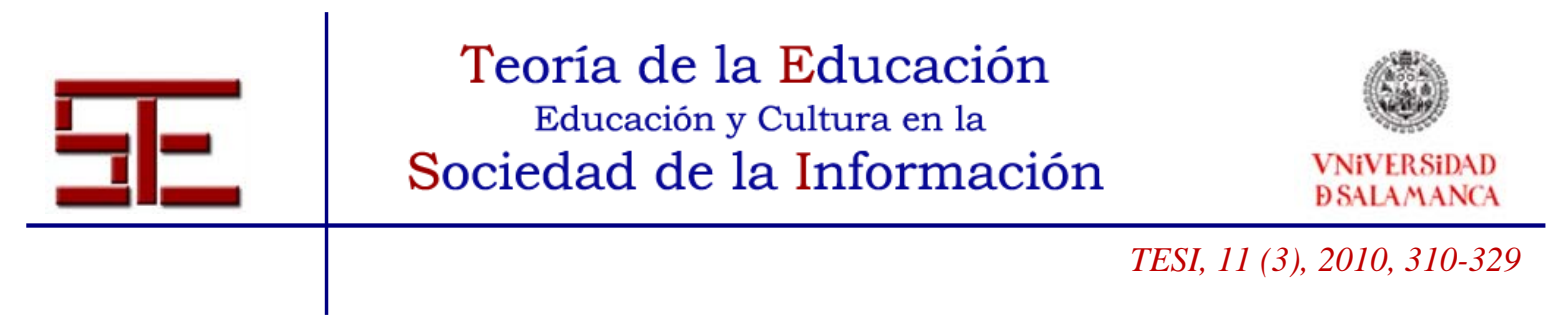

CONSTRUCTIONIST EXPERIENCES WITH EDUCATIONAL ROBOTICS AT THE INTERNATIONAL CENTRE FOR ADVANCED TECHNOLOGIES

\begin{abstract}
:
Digital technology in the education field has two aspects: information and construction. Although, more importance is currently placed upon the information aspect due to the general public's opinion, this article will focus on construction. The construction side has been neglected in the field of digital technology, especially with regard to educational robotics. This is an innovative and necessary learning tool used to support young students, thanks to its all-purpose and multidisciplinary approach.

As an example of good practices in this field, the NTX Robotics Workshops take place at the International Centre of Advanced Technologies (CITA). This constructionist scenario allows participants to learn through activities and games, improving their understanding of technology and boosting their skills, as well as developing their creativity.
\end{abstract}

Key words:

Digital technology, constructionism, educational robotics, LEGO Mindstorms NXT.

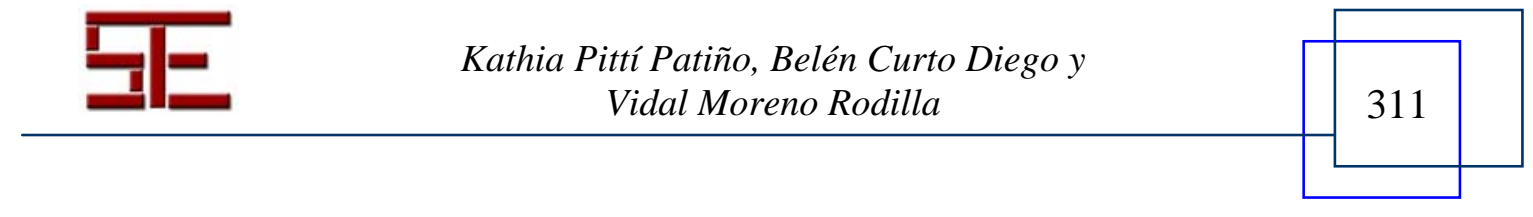




\section{EXPERIENCIAS CONSTRUCCIONISTAS CON ROBÓTICA EDUCATIVA EN EL CENTRO INTERNACIONAL DE TECNOLOGÍAS AVANZADAS.}

Fecha de recepción: 10/10/2009; fecha de aceptación: 27/01/2009; fecha de publicación: 28/02/10

"El aprender mejor no vendrá de ofrecer las mejores herramientas para que el profesor instruya, sino de dar las mejores oportunidades a los estudiantes para construir”.

Seymour Papert

Kathia Pittí

Khatia_pitti@usal.es

Universidad de Salamanca.

Belén Curto Diego

bcurto@usal.es

Universidad de Salamanca

Vidal Moreno Rodilla

vmoreno@usal.es

Universidad de Salamanca

\section{1.- LA TECNOLOGÍA COMO MEDIO DE CONSTRUCCIÓN}

¿En qué piensan las personas cuando escuchan o leen el término "Tecnologías de la Información y la Comunicación (TIC)”? ¿Cómo afecta este pensamiento al sistema educativo?

Para la Fundación Omar Dengo (2006) y Papert (s.f.) el uso masivo de la denominación “Tecnologías de la Información y la Comunicación (TIC)” para referirse, a lo que más adecuadamente se debería llamar "Tecnología Digital", promueve un efecto nocivo sobre la cultura popular y por ende sobre el sistema educativo, al otorgársele mayor importancia a la información y su disponibilidad (Internet), dejando de lado tecnologías de tanta potencialidad educativa como la robótica, la simulación, los hipertextos, por citar algunos ejemplos.

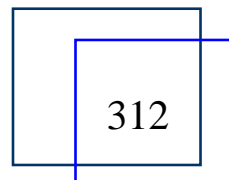

Kathia Pittí Patiño, Belén Curto Diego y Vidal Moreno Rodilla 


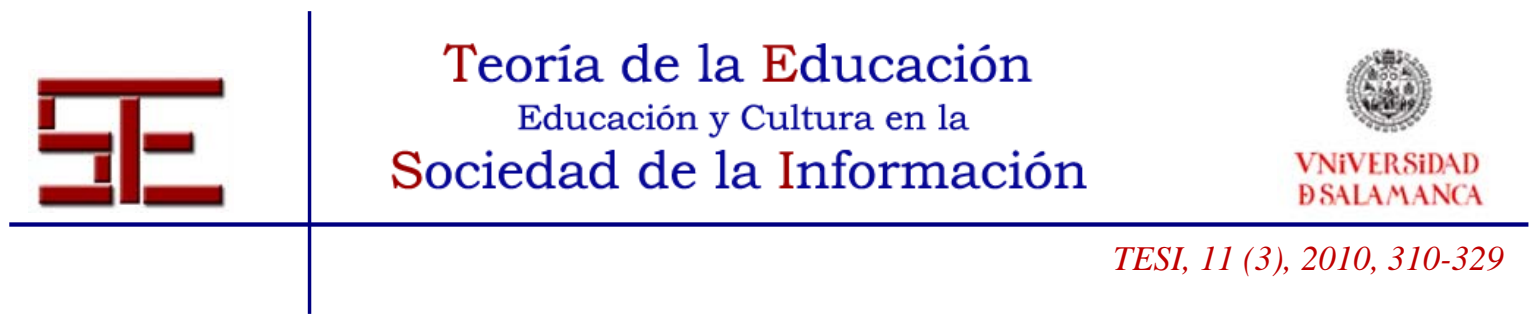

Profundizando un poco, Papert (s.f.) resume en dos los aspectos de la tecnología digital, los mismos que él asocia al ámbito educativo y que son: la tecnología como un medio de información y la tecnología como medio de construcción. Evidentemente, los dos

aspectos son de igual importancia, pero producto de la percepción popular antes mencionada sobre la tecnología digital, el lado constructivo de la educación (hacia dónde debería evolucionar) ocupa un lánguido segundo lugar frente al dominante lado informativo (énfasis actual).

Más aún, la tecnología digital más que para repetir o recibir información, deben emplearse por las personas como un medio expresivo para la creación, es decir, para:

\footnotetext{
"escribir, para dibujar, para hacer música, para animar con movimientos construcciones realizadas por ellos, para controlar sensores o motores, todas acciones con relevancia y propósitos personales, inmersos en un clima de realismo operativo, actuando con y sobre los objetos e interactuando su aprendizaje con el hacer” (Reggini, 2005, párrafo 6).
}

Esta dicotomía generalmente ignorada, entre obtener información y construir cosas, constituye un reto para el sistema actual de enseñanza. Al respecto Papert (s.f., párrafo 17) expresa:

En tanto que la mayor contribución cualitativa que la tecnología digital podría hacer a la educación radica en la corrección de este desequilibrio, en realidad el desequilibrio se incrementa debido a la percepción popular que con tanta fuerza se inclina por la parte informativa tanto de las escuelas como de los computadores.

\section{2.- CONSTRUIR PARA APRENDER}

Seymour Papert crea una visión del aprendizaje a la que denominó “construccionismo”, que es su personal reconstrucción del constructivismo de Piaget $^{1}$, del que fuera discípulo. Para él, lo verdaderamente importante es el papel que pueden desempeñar las construcciones en el mundo (castillo de arena en la playa, un robot o un programa de ordenador) como apoyo a las construcciones mentales. En sus propias palabras "he adaptado la palabra construccionismo, para referirme a todo lo que tiene que ver con hacer cosas y especialmente con aprender construyendo, una idea que incluye la de aprender haciendo, pero que va más allá de ella” (Papert, s.f., párrafo 8).

El construccionismo también es reconocido como una teoría educativa que fundamenta el uso de la tecnología digital en educación (Badilla y Chacón, 2004). Para RuizVelasco $(2007,63)$ se resume en: "Constructivismo + tecnología = Construccionismo”.

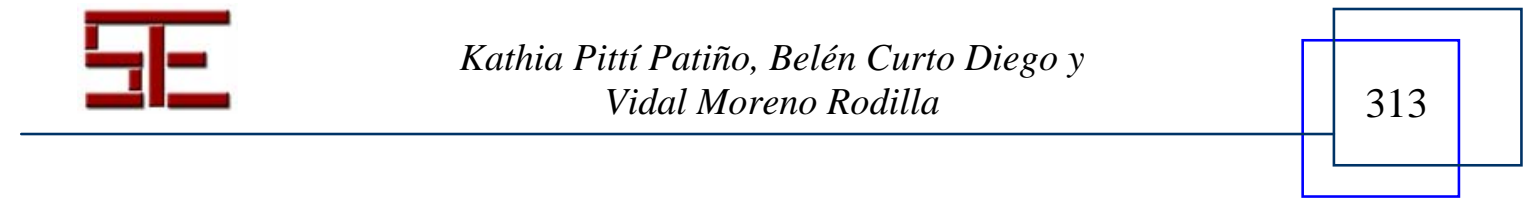




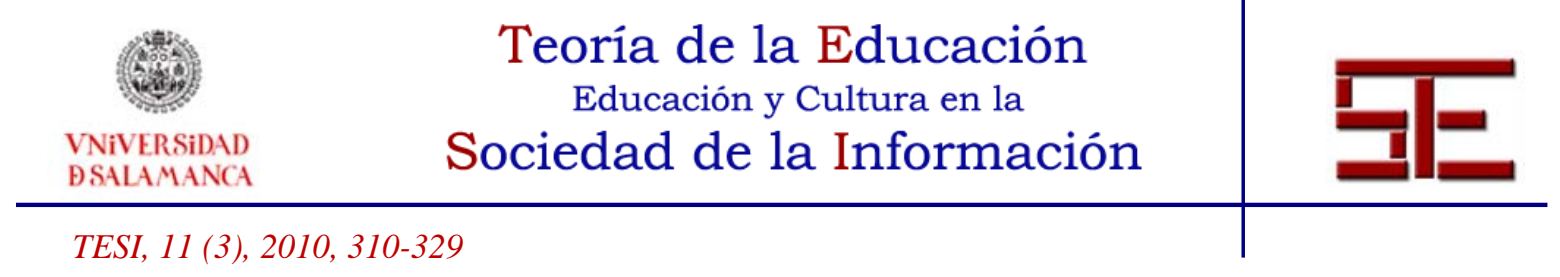

El construccionismo no es sólo una teoría sobre cómo facilitar el aprendizaje de los niños. Se aplica también a los adultos. El construccionismo es un modo de convertir las ideas y relaciones formales y abstractas en más concretas, más visuales, más tangibles, más manipulables y, en consecuencia, más rápidamente comprensibles. Cuando "razonamos con los dedos", liberamos energía creativa, modos de pensamiento y modos de ver las cosas que, de otra forma, nunca podrían liberarse (LEGO education, 2008, 12).

Así pues, Méndez (1995) expone los principios básicos del construccionismo con respecto al:

- Aprendizaje. Tiene lugar desde que se nace, por medio de una interacción dinámica con el mundo físico, social y cultural donde el individuo está inmerso. Asimismo, sostiene que se puede aprender de formas diferentes, sin implicar que unos sean superiores a otros.

- Conocimiento. Es el resultado de las experiencias vividas y del trabajo propio.

- Ambiente. Será adecuado para el desarrollo cognitivo del educando: si le permite enriquecer su trabajo o actividad con sus ideas y motivaciones personales; si está adecuadamente organizado y estructurado; si propicia la creatividad; si además de ofrecer estímulos brinda respuestas a sus acciones, y según el grado de manipulación y actuación que éste le permita.

- Individuo. En un ambiente construccionista disfruta al experimentar con sus ideas, sus razonamientos y hasta sus errores.

- Educador. Debe estar capacitado para reconocer las características propias de cada alumno o alumna y, de acuerdo con ellas, poder proponer las situaciones de enseñanza requerida.

Por otra parte, Badilla y Chacón (2004) describen tres conceptos que se encuentran implícitos en la teoría construccionista de Papert, y que permiten mejores oportunidades de construcción:

- Objetos con los cuales pensar. Se refiere a un objeto que pueda ser utilizado por un sujeto, para pensar sobre otras cosas, utilizando para ello su propia construcción de dicho objeto.

- Entidades públicas. Se les denomina a las construcciones que pueden ser mostradas, discutidas, examinadas o probadas. Este objeto creado, al ser compartido públicamente con los demás, refuerza poderosamente el aprendizaje construccionista.

- Micromundos. Es un pequeñísimo mundo, dentro del cual el aprendiz puede explorar alternativas, probar hipótesis y descubrir hechos que son verdad en relación con ese mundo.

Siguiendo la reflexión anterior "para el construccionismo, el mejor ambiente para aprender es un micromundo, que incluya objetos para pensar (entre ellos computadoras)

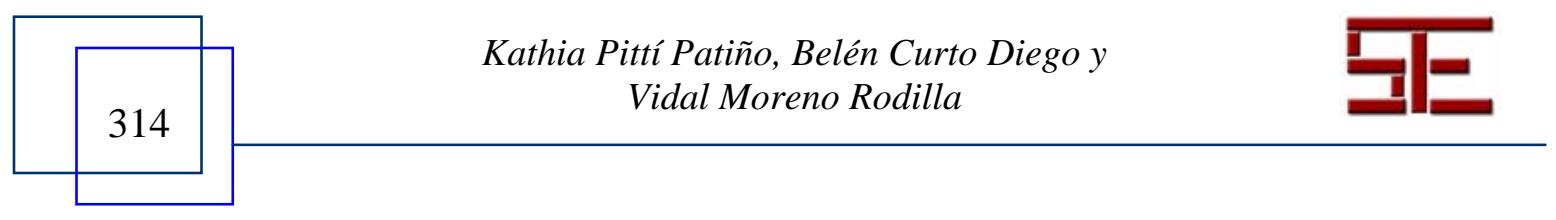




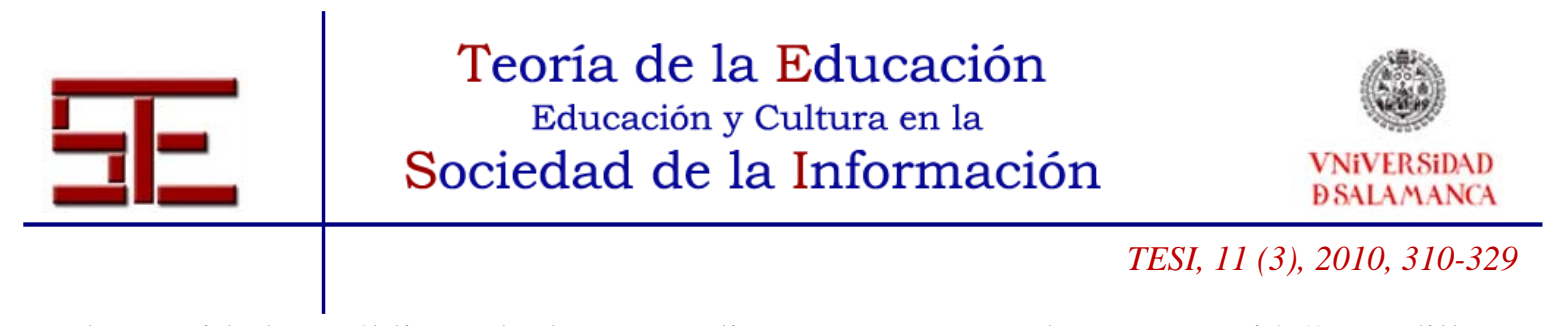

y las entidades públicas de los aprendices, en proceso de construcción” (Badilla y Chacón, 2004, 10).

En definitiva, el fundamento del modelo de desarrollo cognitivo de Papert es:

la creación de una cultura o un ambiente con ciertas características estimulantes y facilitadoras del desarrollo intelectual [...] un enfoque educativo en el que se toma muy en cuenta la personalidad de cada niño o niña, sus intereses, estilo de conocimiento, y en el que se busca proporcionarle una gran autonomía intelectual y afectiva (Méndez, 1995, 120-121).

Es importante destacar, que Seymour Papert fue más lejos que sólo formular la teoría construccionista; él ha dedicado sus esfuerzos a crear objetos con los cuales pensar que puedan producir un cambio radical en el modo en que aprenden los niños. Junto a un equipo de investigadores del Instituto Tecnológico de Massachusetts (MIT), desarrollaron en primer lugar el popular lenguaje de programación LOGO² en 1967; posteriormente sus ideas construccionistas sobre el aprendizaje interesan a la Compañía LEGO y, en colaboración, diseñan una interface que permite conectar la construcción con la programación, surge así la línea LEGO Mindstorms ${ }^{3}$ en 1998.

La simplicidad de uso del kit LEGO Mindstorms al no requerir conocimientos eléctricos ni electrónicos, ha propiciado que, poco a poco aumente su uso en el campo de la educación.

\footnotetext{
Imagina poder construir un robot completo, con sensores, motores, engranajes, reductoras, estructuras, poder programarlo y configurarlo, y todo sin soldar, taladrar, pegar o taladrar tornillos. Pues eso es LEGO-Mindstorms, una forma fácil y sencilla de aprender robótica y construir tu propio robot (Díaz et al., 2006, 6).
}

Por lo tanto, desde nuestro punto de vista, LEGO Mindstorms es en la actualidad el material de construcción más eficaz para comenzar a experimentar con robots y concentrarnos en el aspecto académico del aprendizaje.

Desde el punto de vista de Ruiz-Velazco "aprovechar las bondades que ofrece el estudio de la robótica para la formación de estudiantes y su utilización como objeto de estudio y como medio de enseñanza, resulta realmente un campo vasto, innovador e interesante desde el punto de vista cognoscitivo" $(2007,106)$.

\section{3.- LA ROBÓTICA EDUCATIVA}

\section{1.- Definición}

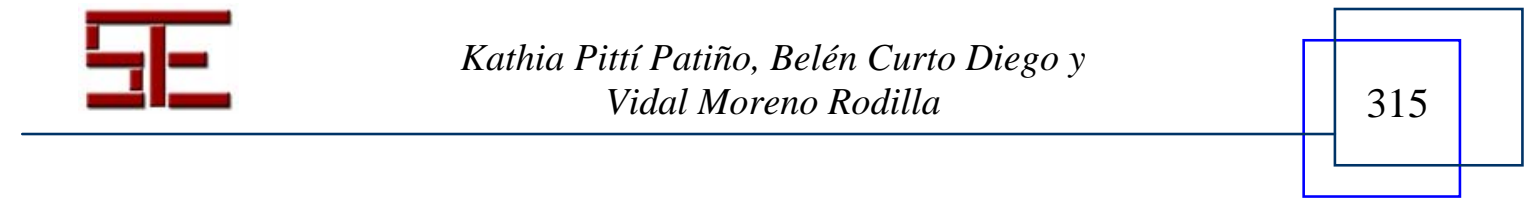




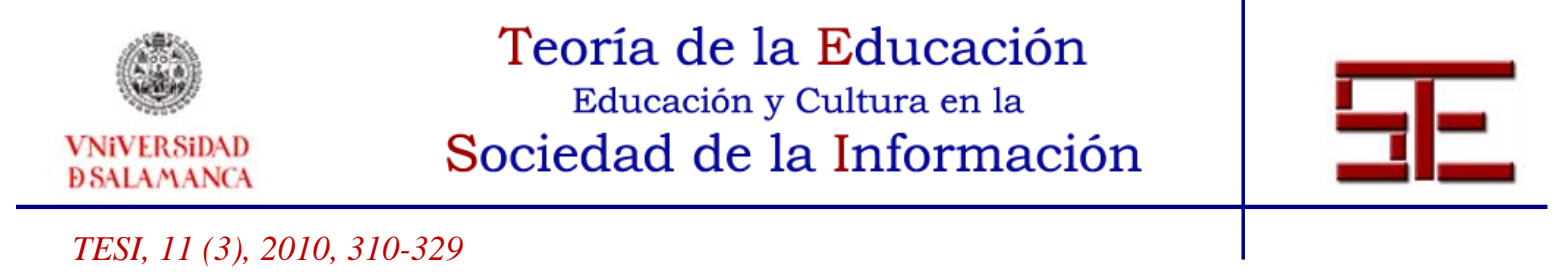

Imaginar que hace una década construir robots para una persona sin estudios universitarios era difícil si no imposible. Gracias a los avances tecnológicos eso ha cambiado y ahora el sistema educativo puede transformar el tradicional ambiente de aprendizaje por uno centrado en la exploración y la construcción, utilizando el potencial didáctico de la robótica educativa, que ha sido definida como:

"un contexto de aprendizaje que se apoya en las tecnologías digitales e involucra, a quienes participan, en el diseño y construcción de creaciones propias, primero mentales y luego físicas, construidas con diferentes materiales y controladas por un computador” (Fundación Omar Dengo, 2007, 11).

"una disciplina que permite concebir, diseñar y desarrollar robots educativos para que los estudiantes se inicien desde muy jóvenes en el estudio de las ciencias y la tecnología” (Ruiz-Velasco, 2007, 113).

"el conjunto de actividades pedagógicas que apoyan y fortalecen áreas específicas del conocimiento a través de la concepción, creación, ensamble y puesta en funcionamiento de robots” (Robótica educativa de México, 2009, párrafo 1).

\section{2.- Carácter polivalente y multidisciplinario}

Un punto clave en el papel que puede llegar a desempeñar la robótica en la transformación de la práctica educativa, está en su carácter polivalente y multidisciplinario, es decir, aprendiendo a diseñar, construir y programar robots se adquieren diferentes conceptos provenientes de distintos campos del saber, como: las matemáticas, las ciencias naturales, la tecnología, entre otras.

Sobre este particular, Edgar Morin (1999), pensador francés de gran impacto en la actualidad, plantea que nuestros conocimientos, son cada vez más especializados y fragmentados, mientras los problemas a los que debemos enfrentarnos, son cada vez más complejos y globales. Según Morin, el sistema educativo contribuye a este desajuste con sus divisiones en ciencias y humanidades, con sus departamentos cerrados y sus disciplinas aisladas, con sus métodos que, desde la misma primaria, tienden a aislar a los objetos de su entorno.

Por consiguiente, la transdisciplinariedad ${ }^{4}$ de la robótica educativa aporta unos espacios, unas nuevas miradas y unos escenarios que hacen posible la innovación didáctica interdisciplinar.

\section{3.- Aportes de la robótica educativa}

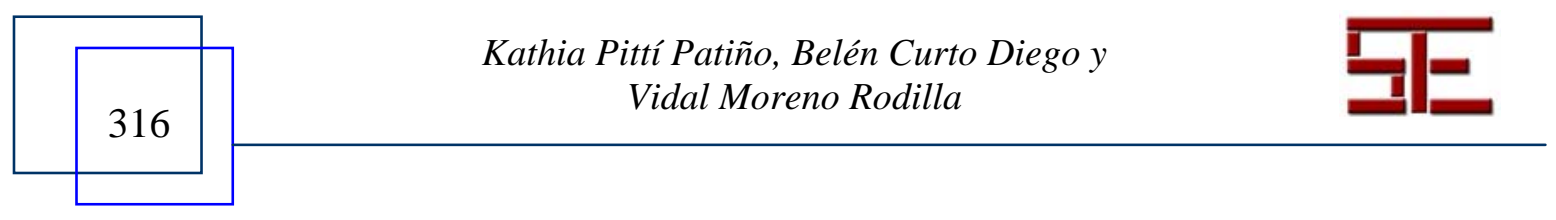




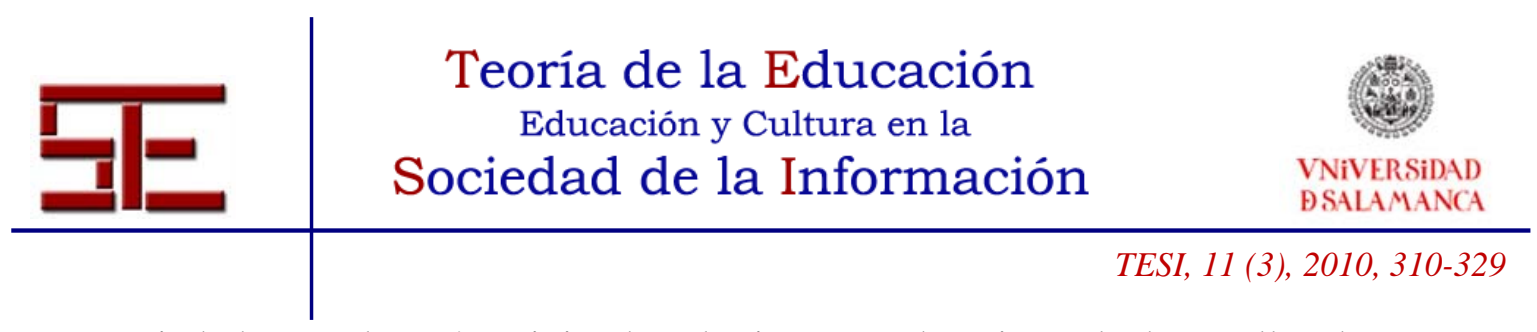

La sociedad actual está exigiendo al sistema educativo el desarrollo de nuevas competencias y habilidades que preparen exitosamente a los estudiantes para la vida, el aprendizaje y el trabajo.

Howard Gardner (2005), creador de la teoría de las inteligencias múltiples, describe cuáles serán las cinco mentes del futuro, es decir, las cinco capacidades que deberíamos desarrollar para enfrentar el siglo XXI: la mente disciplinada, la mente sintetizadora, la mente creadora, la mente respetuosa y la mente ética. Las tres primeras relacionadas con aspectos cognitivos y las dos últimas mentes tienen que ver con nuestras actitudes y valores, y con cómo nos relacionamos con los demás, esto es, con la formación del carácter y la clase de ser humano que cada uno es.

\footnotetext{
en un mundo caracterizado por la hegemonía de la ciencia y la tecnología, la transmisión global de enormes cantidades de información, la realización de tareas rutinarias por ordenadores y robots y los contactos de todo tipo y cada vez mayores entre poblaciones diversas. Quienes logren cultivar esta pentarquía de mentes tienen más probabilidades de prosperar y salir adelante (Gardner, 2005, 226).
}

El propósito de la robótica educativa no es necesariamente enseñar a los estudiantes a convertirse en expertos en robótica, sino más bien, como señalan diversas investigaciones y autores (Acuña, 2007; Goh y Aris, 2007; LEGO educational, 2008; Ruiz-Velasco, 2007), es favorecer el desarrollo de competencias que son esenciales para el éxito en el siglo XXI, como: la autonomía, la iniciativa, la responsabilidad, la creatividad, el trabajo en equipo, la autoestima y el interés por la investigación.

La robótica da vida a la ingeniería, las matemáticas, la computación y las vuelve tangibles. Es una manifestación concreta de la solución de problemas que recompensa la ingeniosidad, la persistencia y la capacidad de encontrar y corregir errores. Los materiales de robótica de LEGO ofrecen posibilidades de improvisación que permiten incluso a niños pequeños construir una máquina, someter a prueba una hipótesis, "cacharrear”, corregir errores y superar sus expectativas. Este diálogo con la máquina amplifica e intermedia la conversación con él mismo. El LEGO contribuye, con su posibilidad de improvisación, al pensamiento de los estudiantes (Stager, s.f., párrafo 20).

Otro aspecto a considerar de la robótica educativa, es su capacidad de fomentar el interés por vocaciones científicas, creándoles a los estudiantes una visión de la ciencia y la tecnología atractiva y dinámica (Goh y Aris, 2007; Ruiz-Velasco, 2007).

La utilidad didáctica que puede proporcionar la robótica educativa es amplia. Al ser una herramienta versátil, admite diversas formas de utilización según los objetivos y la asignatura, valorándose especialmente por permitir a los profesores y a los estudiantes modificar su contenido y adaptarlo a sus necesidades concretas.

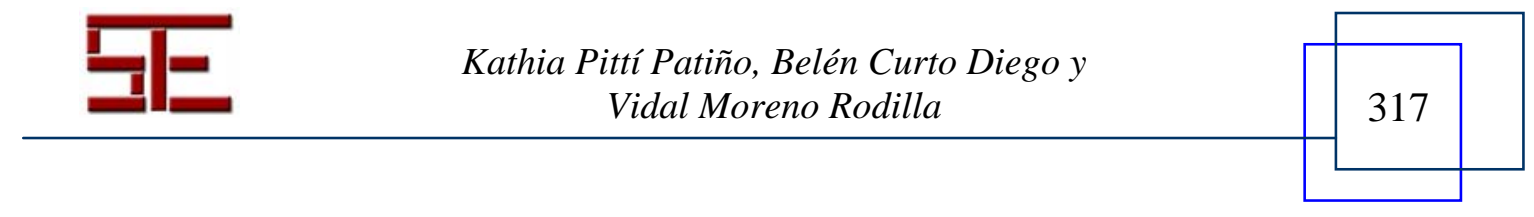




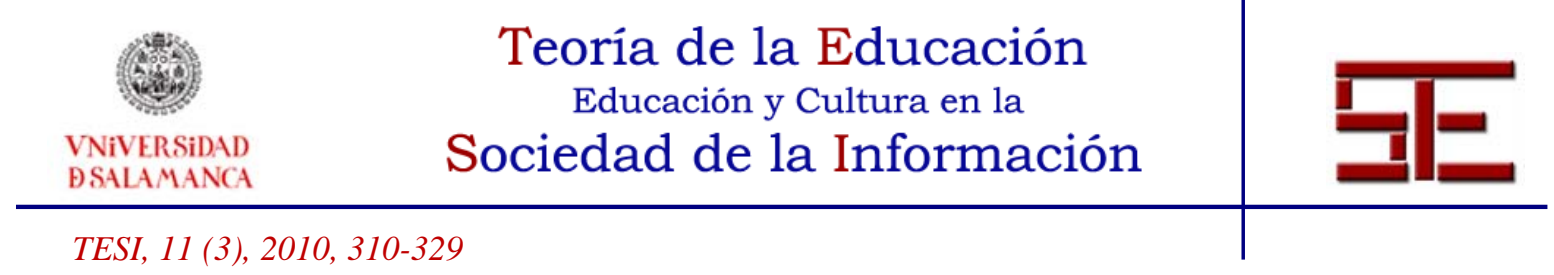

Sin embargo, como elementos que condicionan su utilidad pedagógica tenemos:

- Elección del material: software de programación, coste económico, documentación de apoyo, posibilidades de la herramienta, etc.

- Alumnado: uso habitual, actitud y predisposición, habilidad, etc.

- Educador: creencias y formación adicional requerida.

- Currículo: objetivos, contenidos, actividades, evaluación, etc.

- Instalaciones: mobiliario existente, disposición, etc.

Los desafíos que plantea la utilización de la robótica educativa en la enseñanza, así como los resultados obtenidos dentro de las actividades extraescolares serán analizados en los siguientes apartados.

\section{4.- LOS TALLERES NXT COMO MICROMUNDOS DE APRENDIZAJE}

En párrafos anteriores, enfatizamos la importancia de usar en educación la tecnología digital como medio de construcción, es decir, mediante la realización de experiencias construccionistas que promuevan el desarrollo de las competencias y las habilidades que demanda este milenio en sus ciudadanos.

Para alcanzar este propósito es necesario diseñar nuevos ambientes de aprendizaje, nuevos "micromundos" como los denomina Papert, que incluyan herramientas para la exploración (objetos con los cuales pensar) y que dicha exploración lleve a la construcción de conocimientos. Badilla y Chacón resaltan que "un micromundo constituye por sí mismo una entidad pública y que utiliza como herramientas para su construcción objetos para pensar” (2004, 8).

Así pues, encontramos en la teoría construccionista la base educativa de los talleres $N X T$, de estos micromundos de aprendizaje que permiten a los participantes mejorar su comprensión de la tecnología, potenciar habilidades y desarrollar la creatividad. Su nombre se debe al "objeto con el cual pensar" que se emplea en los talleres, el nuevo modelo para la construcción de los robots LEGO Mindstorms llamado NXT. Este incluye las piezas típicas de LEGO que permiten construir diferentes estructuras robóticas, sensores para la percepción del exterior, motores para conseguir el movimiento del robot y el micro-computador NXT para la programación de sus acciones. Estas percepciones y movimientos constituyen el lenguaje para la comunicación del robot con su entorno.

La variedad de talleres $N X T$ va desde robots que compiten en el tradicional juego del pañuelo, encestan la pelota jugando un partido de baloncesto, luchan en un combate de sumo, disputan carreras en una pista simulando la fórmula 1 y hasta robots con habilidades para dibujar. Para que el robot pueda desarrollar cada una de estas

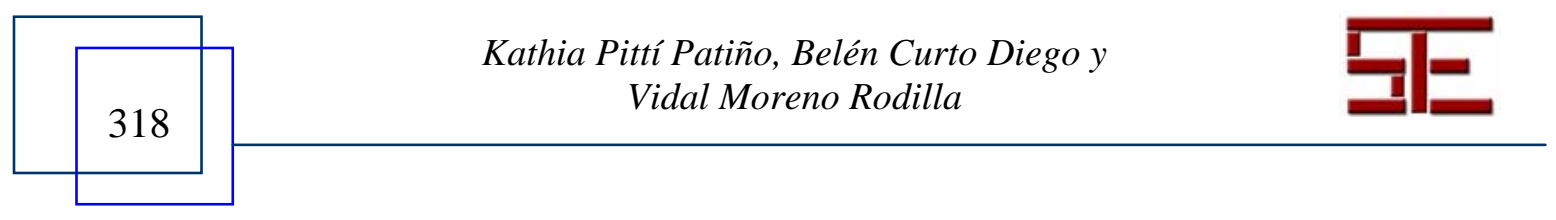




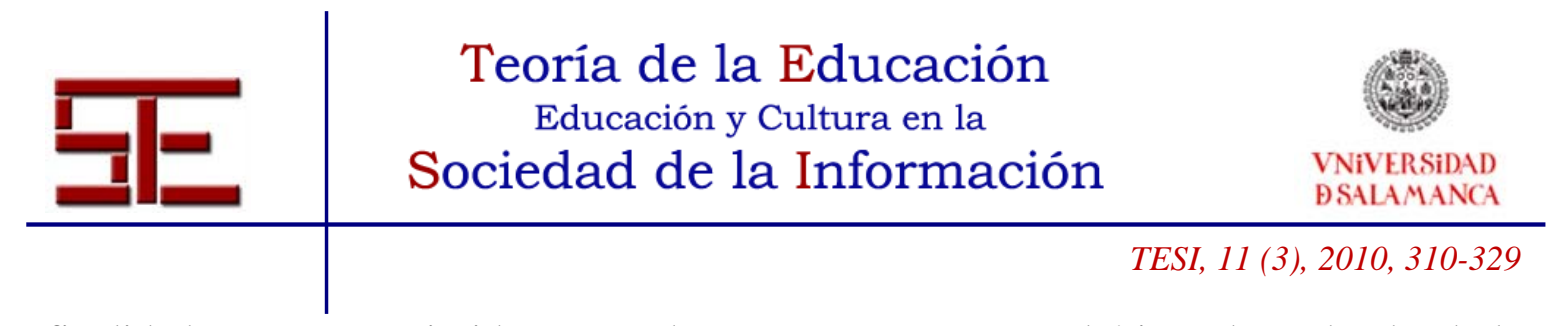

finalidades, es necesario idear en cada caso una estructura robótica adecuada, donde la creatividad de los participantes juega un papel fundamental.

Los talleres NXT finalizan con una actividad donde los participantes describen el robot que han construido ante sus familiares y amigos; posteriormente se realiza una competición o una exhibición. El robot, al ser compartido con otras personas, refuerza considerablemente el aprendizaje.

\section{5.- METODOLOGÍA DE LOS TALLERES NXT}

\section{1.- Introducción}

El Centro Internacional de Tecnologías Avanzadas (CITA http://www.citafgsr.org/cita/) de la Fundación Germán Sánchez Ruipérez en Peñaranda de Bracamonte (Salamanca) se inauguró en octubre de 2006 y es la sede de los talleres NXT.

Uno de sus principales objetivos es la incorporación de la tecnología digital al ámbito educativo, tratando de dotar a cada uno de sus proyectos formativos de los últimos avances, tanto a nivel metodológico como tecnológico, para alcanzar un alto grado de innovación educativa. En este sentido, se realizan los talleres $N X T$, organizados por la Fundación Germán Sánchez Ruipérez, a través del CITA, y el Ayuntamiento de Peñaranda de Bracamonte.

El instructor de los talleres NXT es Román Ontiyuelo, un apasionado de la robótica. Su principal objetivo al diseñar e impartir estos talleres es acercar y fomentar el mundo de la robótica tanto a los niños como a los adultos, permitiendo la construcción y programación de robots NXT. A partir del 2009, Kathia Pittí colabora en los talleres NXT. Desde el inicio del proyecto en el 2006, han pasado cerca de 22 niños y 31 adultos, en un total de 9 talleres (ver Tabla 1).

\section{2.- Primera etapa: diseño del taller}

Cada taller es el resultado de una planificación metódica por parte del instructor Román Ontiyuelo y la colaboración de CITA, entre los puntos a tener en cuenta están:

- Elección del tema. Es el primer paso en el diseño del taller. Entre las fuentes de inspiración podemos mencionar: competiciones, eventos, libros e Internet. Además, en los últimos talleres les consultamos a los propios participantes sobre los temas que desearían encontrar.

- Diseño y construcción del robot. Un factor clave es el nivel de libertad que los participantes tienen a la hora del diseño del robot. Hemos planteado tres

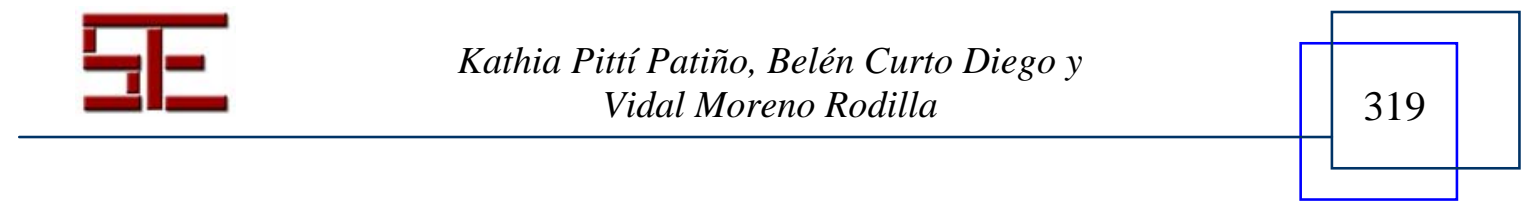




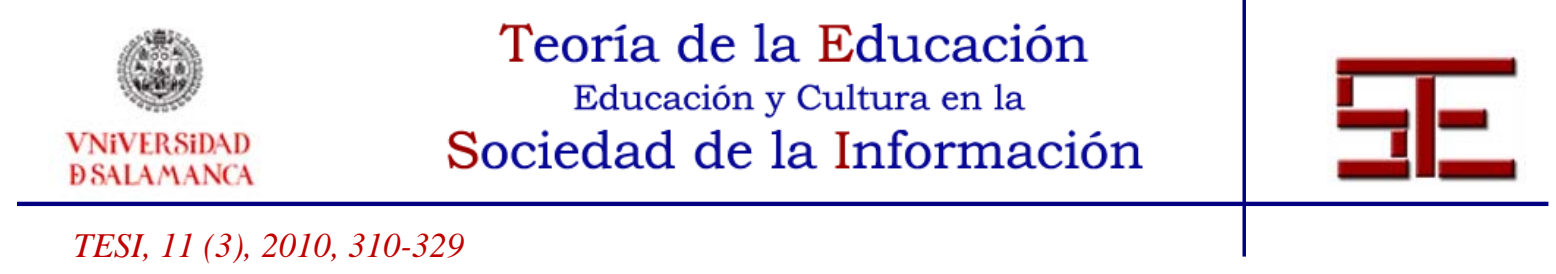

grados de dificultad: un diseño guiado (nivel de iniciación), es decir, ya preestablecido; creación libre, creatividad al 100\%; y el tercero es una combinación de los dos anteriores.

- Instalaciones. Este otro factor importante: siempre tratamos de lograr el mejor aprovechamiento del espacio en el cual trabajamos. Así, en ocasiones necesitamos reubicar el mobiliario según la actividad (Figura 1).

- Material a utilizar. La cantidad de kits de trabajo disponibles va a determinar el número de grupos en el taller. Los participantes son organizados en equipos hasta de tres personas según sus preferencias, brindando así, un ambiente propicio para el desarrollo de las habilidades colaborativas, sociales y afectivas.

- Nivel de dificultad (iniciación, medio, avanzado). Este punto indica el nivel de destrezas necesarias, tanto de construcción como de programación, que el participante debe tener para lograr un mejor resultado de los objetivos propuestos.

- Guía didáctica. Un cuadernillo para cada participante donde encontrará la información del taller: sus objetivos, actividades y programación de cada sesión.

- Cronograma. Programar y distribuir el contenido del taller según la cantidad de sesiones es un elemento obligatorio para el éxito del mismo. No obstante, siempre es mejor contar con tiempo adicional, al observar que la motivación de los participantes es tan alta que no desean terminar.

Como se observa, muchos de los puntos se interrelacionan, pero cuanto más tiempo dedicamos a esta etapa, mejores resultados podremos esperar de las demás.

La propuesta terminada del taller es enviada a CITA con antelación, para su aceptación y divulgación a través de diferentes medios: correo electrónico, prensa, carteles o folletos informativos.
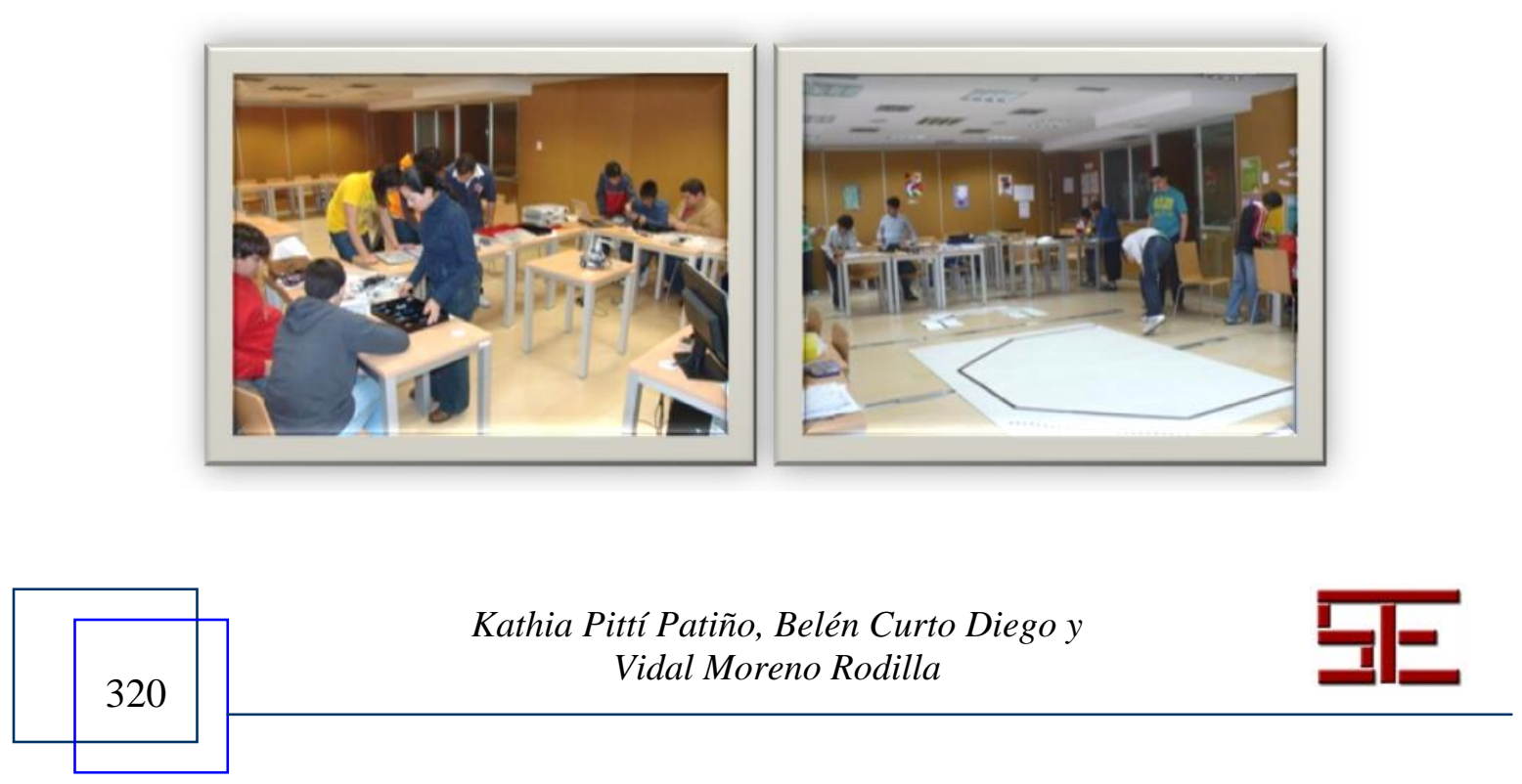


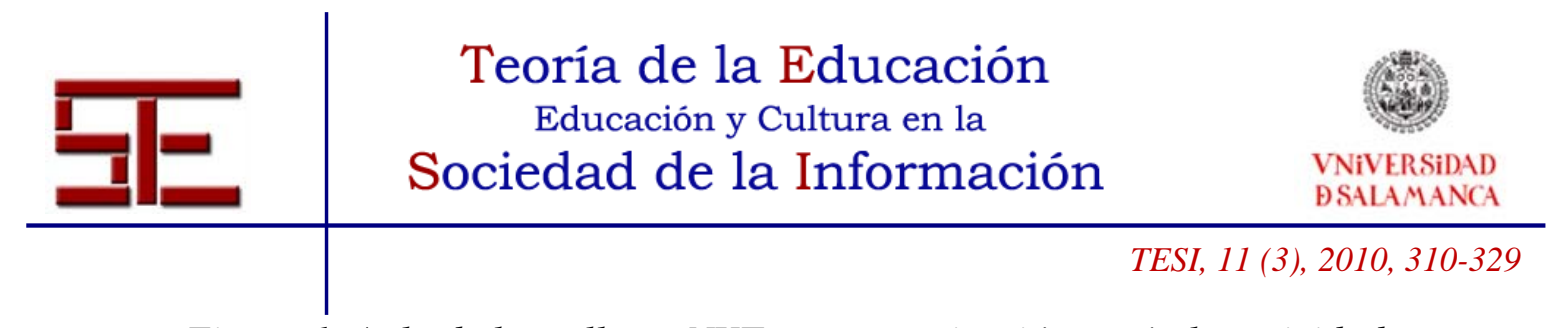

Figura 1. Aula de los talleres NXT y su organización según la actividad

La tabla 1 recoge los talleres $N X T$ ofrecidos hasta la fecha y datos relevantes de los mismos.

\begin{tabular}{|c|c|c|c|}
\hline Año & Título & Objetivo & Nivel \\
\hline 2006 & $\begin{array}{l}\text { Introducción a la } \\
\text { robótica }\end{array}$ & $\begin{array}{l}\text { Diseñar, programar, testear y competir con } \\
\text { robots realizados por ti mismo. }\end{array}$ & Iniciación \\
\hline 2007 & $\begin{array}{l}\text { Construye tu } \\
\text { robot }\end{array}$ & $\begin{array}{lcr}\begin{array}{l}\text { Construir su } \\
\text { determinadas } \\
\text { establecidas. }\end{array} & \begin{array}{c}\text { propio robot } \\
\text { acciones }\end{array} & \begin{array}{r}\text { programar } \\
\text { previamente }\end{array} \\
\end{array}$ & Iniciación \\
\hline 2007 & $\begin{array}{l}\text { El poder de la } \\
\text { robótica en tus } \\
\text { manos } \\
\end{array}$ & $\begin{array}{l}\text { Diseñar, programar y montar un robot propio } \\
\text { de una forma autosuficiente y entretenida. }\end{array}$ & Iniciación \\
\hline 2007 & BASKETBOT & $\begin{array}{l}\text { Construir un robot NXT que sea capaz de } \\
\text { seguir una línea negra, situarse delante de una } \\
\text { canasta y realizar un tiro a ésta. }\end{array}$ & Media \\
\hline 2008 & PAINTBOT & $\begin{array}{l}\text { Diseñar un robot con la habilidad de pintar } \\
\text { líneas y diferentes figuras geométricas sobre } \\
\text { un lienzo con la ayuda de un pincel. }\end{array}$ & Iniciación \\
\hline 2008 & SUMOBOT & $\begin{array}{l}\text { Diseñar y construir un robot SUMO, } \\
\text { programando una serie de estrategias de } \\
\text { ataque y defensa. }\end{array}$ & Avanzado \\
\hline 2008 & ZOO NXT & $\begin{array}{l}\text { Construir animales (elefante, caimán, } \\
\text { serpiente, dinosaurio, etc.) y programarlos, } \\
\text { imitando sus comportamientos más habituales. }\end{array}$ & Iniciación \\
\hline 2009 & Fórmula 1 NXT & $\begin{array}{l}\text { Construir y programar su propio vehículo } \\
\text { NXT®. }\end{array}$ & Iniciación \\
\hline 2009 & $\begin{array}{l}\text { First Lego } \\
\text { League }\end{array}$ & $\begin{array}{l}\text { Participar en la competición “Smart Move” en } \\
\text { Madrid. }\end{array}$ & Media \\
\hline \multicolumn{4}{|c|}{$\begin{array}{c}\text { Material necesario: } \\
8527 \text { Mindstorms }{ }^{\circledR} \text { NXT® Kit } \\
9797 \text { Mindstorms }{ }^{\circledR} \text { NXT® Kit } \\
\text { Piezas extras }\end{array}$} \\
\hline
\end{tabular}

Tabla 1. Talleres NXT impartidos en CITA

\section{3.- Segunda etapa: realización del taller}

Para Román Ontiyuelo, cuando los chicos y las chicas construyen y experimentan, ellos están viviendo el proceso completo de crear ideas, resolver problemas y superar obstáculos.

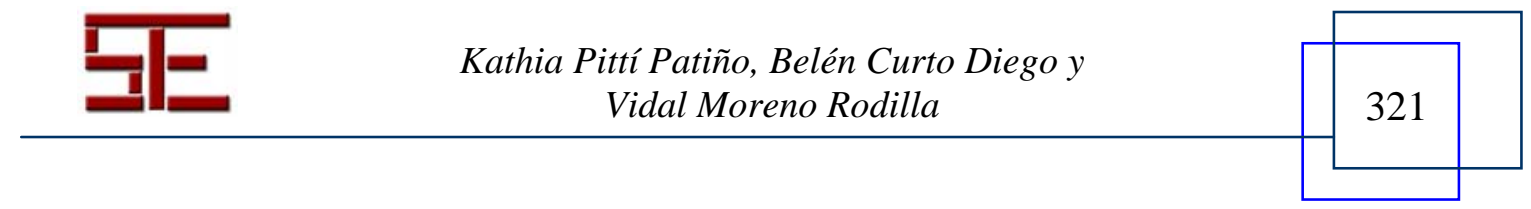




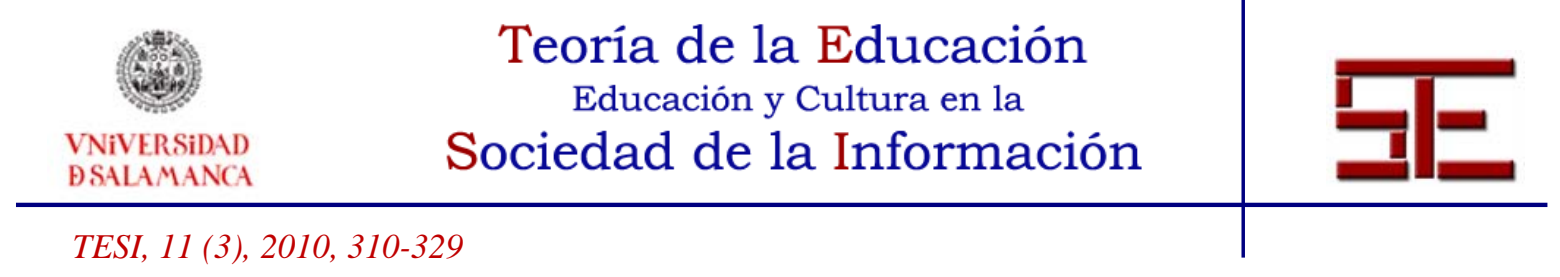

Igualmente señala, que "los talleres NXT ayudan a formarse una percepción positiva sobre la ciencia y la tecnología”.

Para la construcción de un robot se necesitan una serie de pasos que van a permitir que éste pueda realizar sus actividades. Desde el diseño, la construcción de la base, el acoplamiento de los distintos accesorios, su programación, finalizando con la fase de

prueba del robot hasta conseguir la precisión deseada, requiere un esmerado trabajo, tanto por parte de los instructores como por los participantes.

El horario de los talleres suele ser de 11 de la mañana a 14 de la tarde, durante cinco sesiones sabatinas, estructuradas generalmente así:

Sesión 1: presentación del curso, creación de equipos y familiarización con las piezas del kit de LEGO.

Sesión 2: diseño y elección del modelo deseado.

Sesión 3: montaje, ya sea una construcción totalmente guiada, libre o mixta.

Sesión 4: programación, utilizando el lenguaje gráfico de programación NXT-G y a veces el lenguaje textual NXC, dependiendo del nivel de dificultad.

Sesión 5: montaje de la pista de competición o exhibición, pruebas previas y competición final (por la tarde).

Cabe destacar que cada sesión comenzamos repasando los conceptos y aspectos más significativos de las sesiones previas. Además, como elemento motivador mostramos videos y realizamos mini-actividades con material referente a los contenidos del curso.

En la sesión de programación del robot, el instructor explica grupo a grupo cómo se construye un programa NXT-G o NXC, y cómo se descarga éste al robot, así cómo modificar dicho programa para realizar posibles mejoras de comportamiento.

Una característica de todos los talleres NXT es la actividad de cierre (Figura 2), realizada por la tarde. Se trata de que los participantes hagan una demostración de las habilidades de su robot o compitan entre ellos, dependiendo de la finalidad del robot. Esta actividad tiene una asistencia libre y gratuita para apreciar en directo las construcciones robóticas de los participantes. Según comenta el instructor Román Ontiyuelo, "el objetivo es que los participantes finalicen el taller de una manera divertida, acompañados por sus amigos y familiares, y pasen un rato de emoción en una competencia sana”.

En esta actividad los participantes explican al público las características del diseño realizado y, posteriormente, dependiendo del objetivo del taller se realiza una

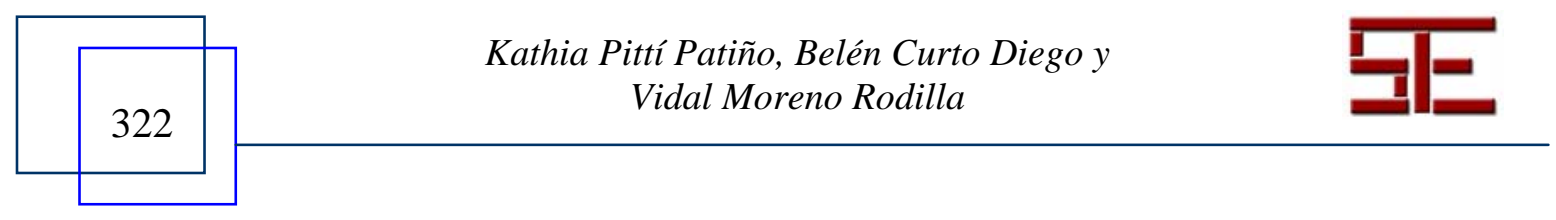




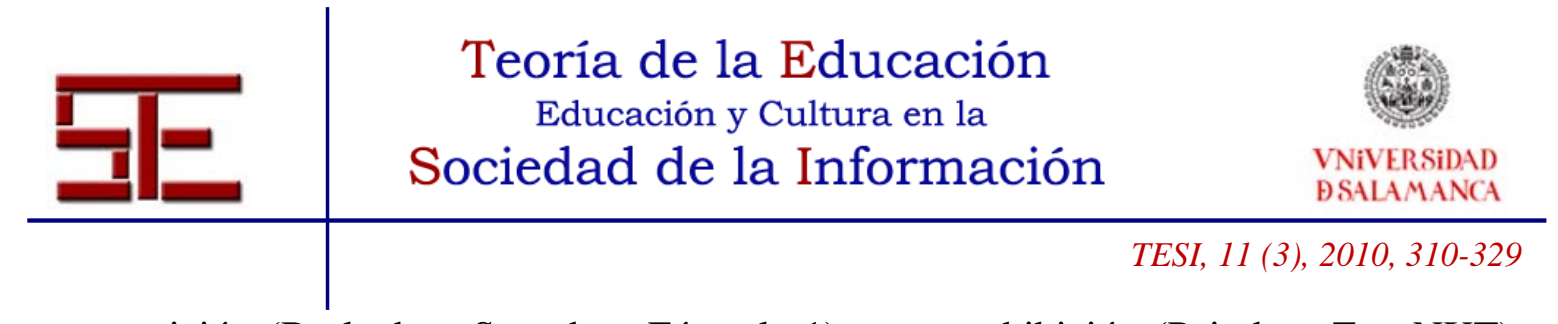

competición (Basketbot, Sumobot, Fórmula 1) o una exhibición (Paintbot, Zoo NXT). Al finalizar se otorgan certificados a todos los inscritos y un obsequio significativo por su participación.

A modo de ejemplo indicamos las actividades realizadas en el taller PAINT BOT:

1.- Elige el nombre de tu equipo.

2.- Elige el nombre de tu robot.

3.- Construye tu mascota robot.

4.- Dibuja tu robot.

5.- Construcción del robot NXT.

6.- Enumerar las acciones de tu robot.

7.- Programar el robot según la lista de acciones.

8.- Presentación de tu robot en público.

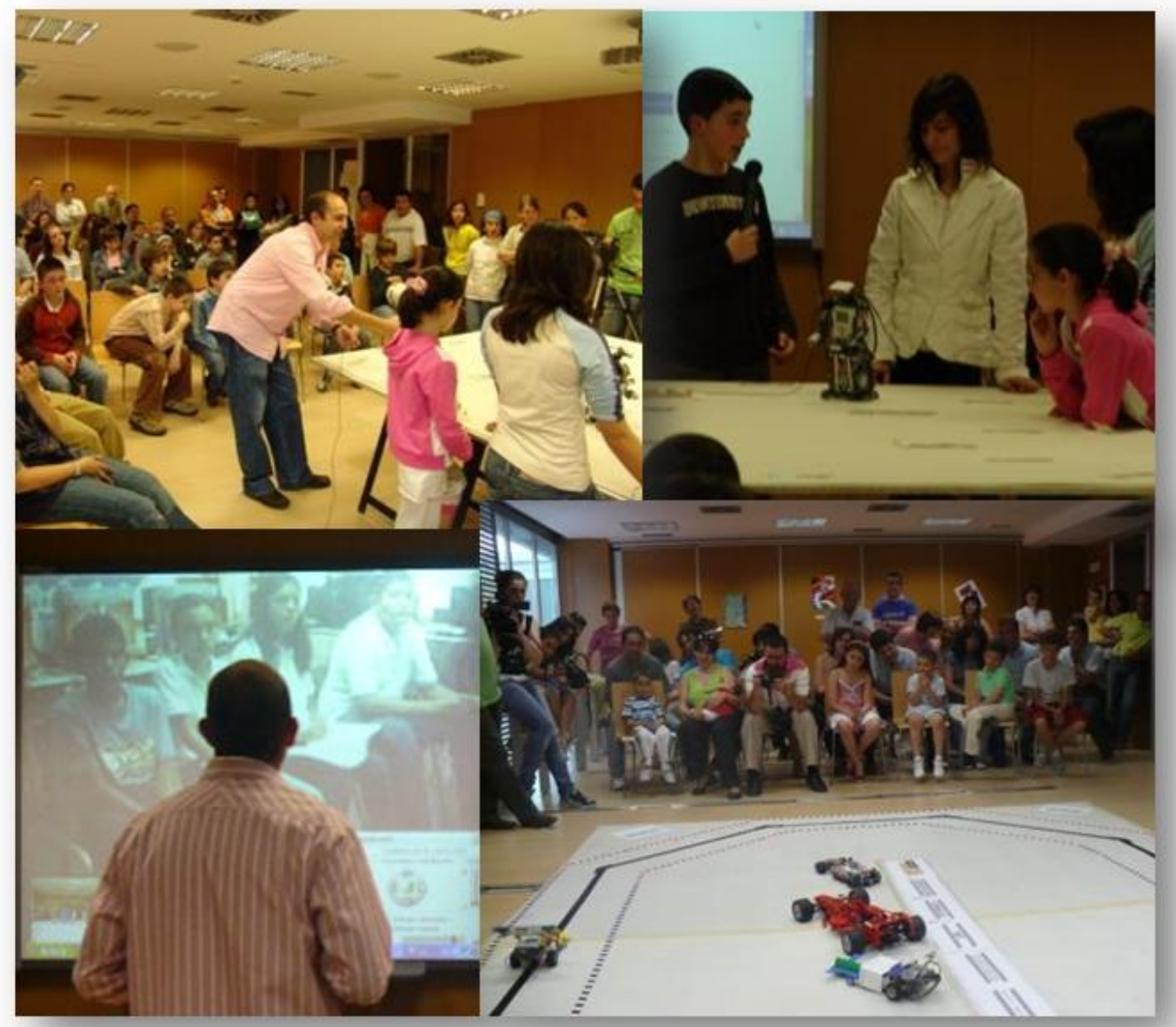

Figura 2. Actividad de cierre de los talleres NXT

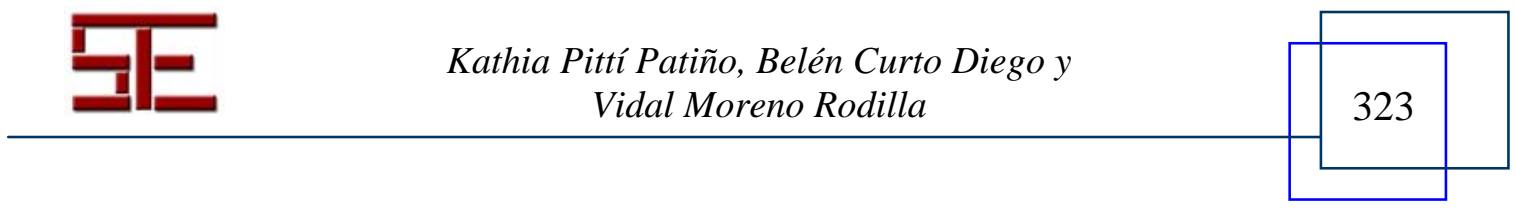




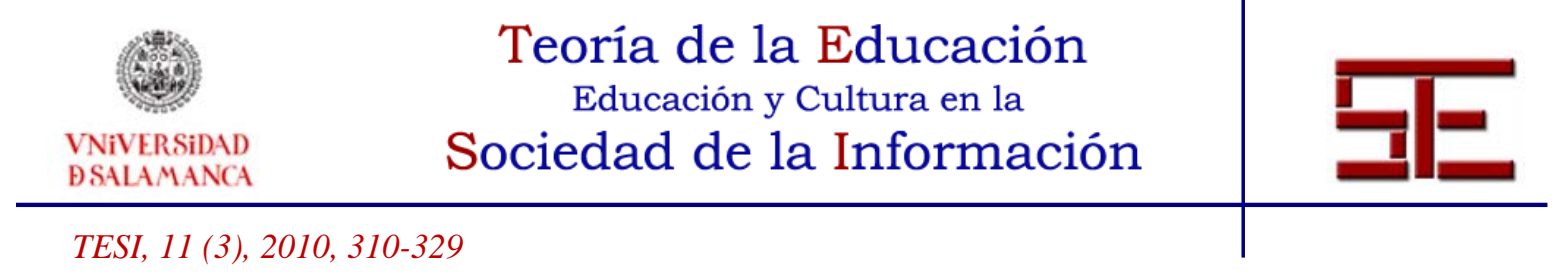

En dos ocasiones la metodología de trabajo se enriqueció, gracias a las facilidades y tecnología con que cuenta CITA, al realizar una videoconferencia con el grupo de robótica del Colegio San Judas Tadeo de República Dominicana, donde al igual que el público presente disfrutaron de la exhibición robótica.

Compartir en red es un factor importante en nuestros días y los talleres NXT cuentan con sus propios blogs que han ido renovándose con los años (muy pronto contarán con su propio espacio web dentro de CITA):

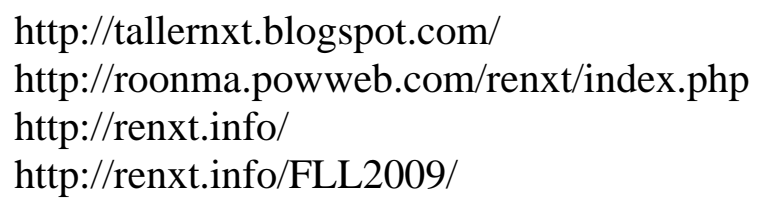

En ellos se puede consultar los talleres realizados, las actividades con sus fotografías, comentarios y vídeos sobre la evolución de todos los participantes.

\section{4.- Tercera etapa: evaluación del taller}

La evaluación es la oportunidad para que tanto los participantes como el instructor, juzguen la calidad y el éxito del taller. Esta se realiza en la quinta sesión mediante encuestas de evaluación de un folio acordes a la edad de los participantes. Los datos recogidos se pueden agrupar en tres categorías:

- Desarrollo del curso (organización, contenido, medios audiovisuales, instalaciones, duración, horario, material didáctico, calificación del taller).

- Instructor (metodología empleada, fomento del trabajo en equipo, comunicación).

- Participante (nivel de motivación, la asimilación de contenido, expectativas cubiertas, sugerencias).

Es esencial que el instructor reciba realimentación de los participantes, en cuanto a la efectividad del taller. Y también es importante que los participantes tengan la oportunidad de hacer sus sugerencias y reflexionar sobre lo que han aprendido. Basándose en esta evaluación el instructor puede delinear y enriquecer la estructura del curso, para próximas ediciones.

\section{6.- LECCIONES APRENDIDAS}

Durante estos cuatro años realizando los talleres $N X T$, las experiencias adquiridas han sido muchas y muy gratas. Consideramos que compartirlas puede enriquecer otras

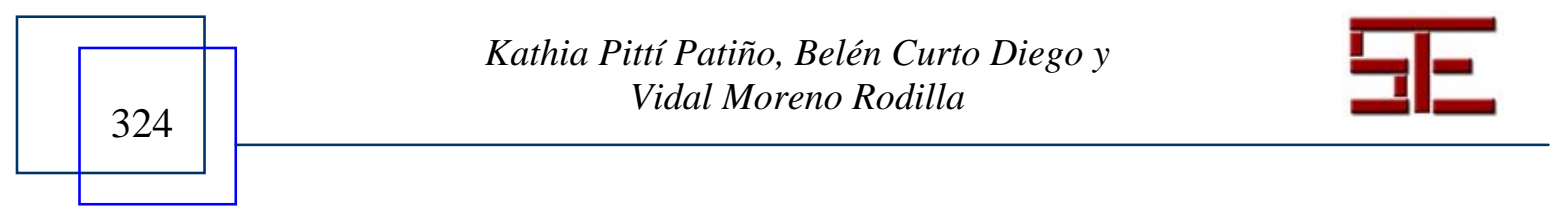




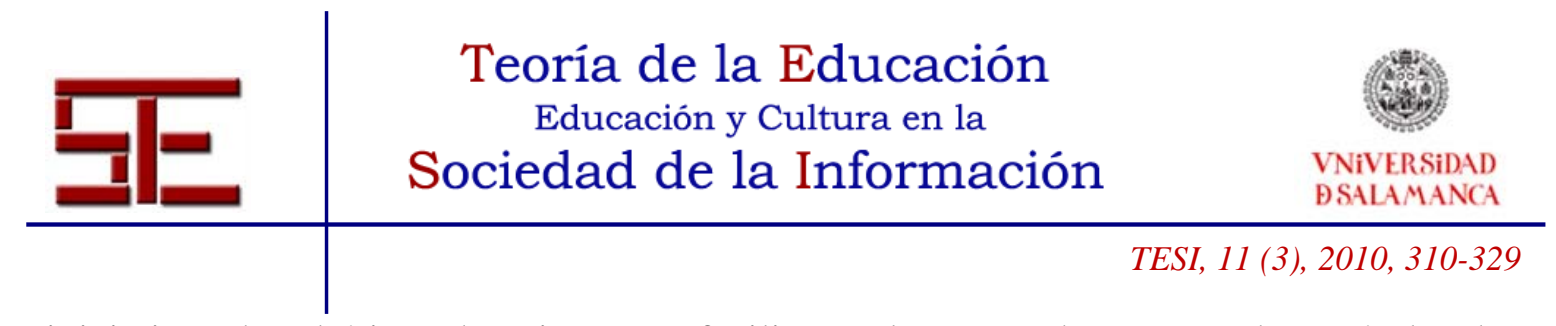

iniciativas de robótica educativa. Para facilitar su lectura se han agrupado según las dos primeras etapas planteadas en la metodología.

\section{1.- Primera etapa: diseño del taller}

- Elección del tema. Puede ser un factor discriminador en cuanto al género de los participantes. En talleres como Basketbot y Sumobot, la participación femenina fue nula, a diferencia de Paintbot y Zoo NXT.

- No existen limitaciones de edad. En el interesante campo de la tecnología digital, como es el caso de la robótica, cualquier edad es buena para aprender, el único requisito según nuestra experiencia es poseer motivación intrínseca.

- Diseño y construcción del robot. Si se utiliza un diseño guiado, recomendamos que éste se pueda complementar con accesorios que permitan mezclar la robótica con el arte para fomentar la creatividad (Figura 3).

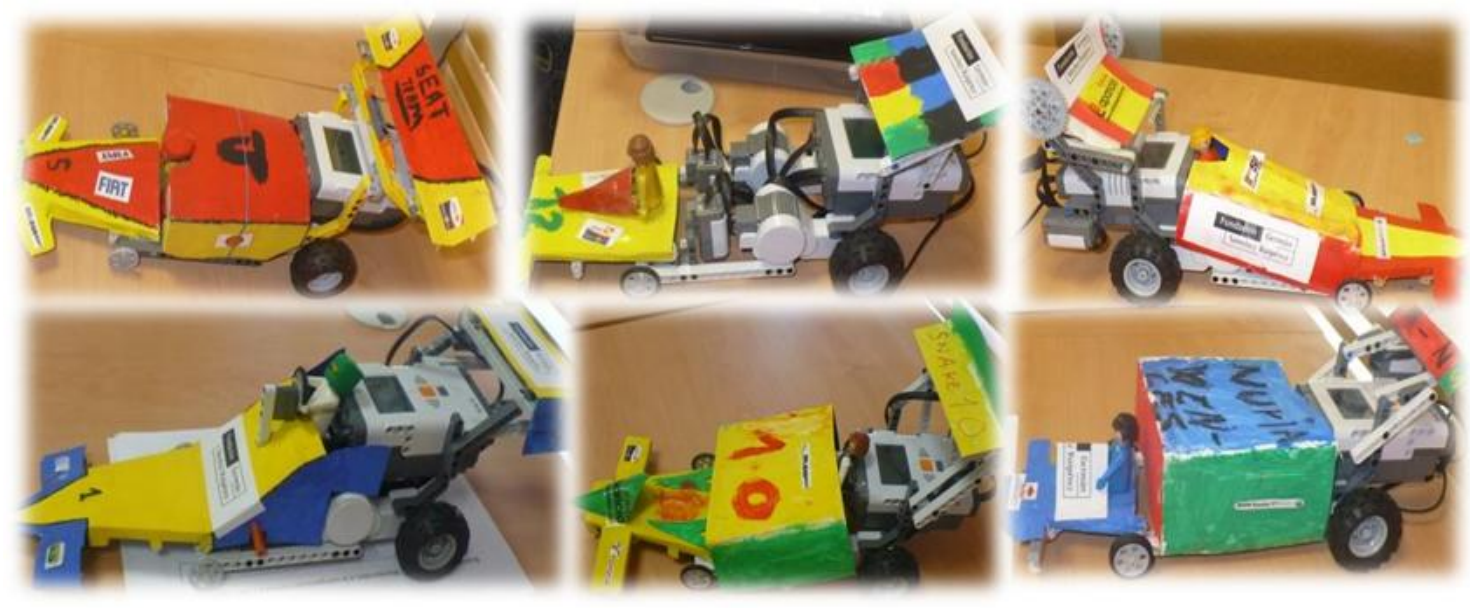

Figura 3. Combinando la robótica con el arte en el Taller de Fórmula 1 NXT

\section{2.- Segunda etapa: realización del taller}

La teoría del construccionismo sostiene que el aprendizaje sucede de forma más poderosa cuando los estudiantes se comprometen en la construcción de productos que sean significativos para ellos. Por tal motivo, lo fundamental de esta etapa es proporcionar a los participantes las oportunidades de realizar actividades creativas que impulsen este proceso constructivo. Para ello desde que se inicia el taller es necesario crear analogías entre la tecnología y el mundo real, es decir:

- Sentido de pertenencia. Cada equipo elige su nombre y el de su robot relacionado con el tema del taller.

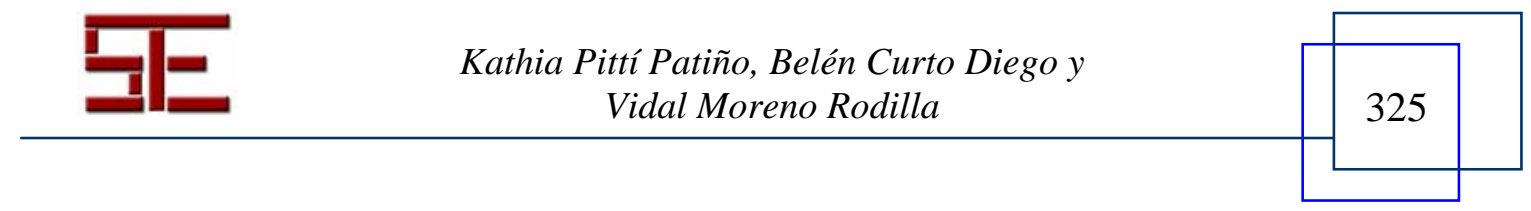




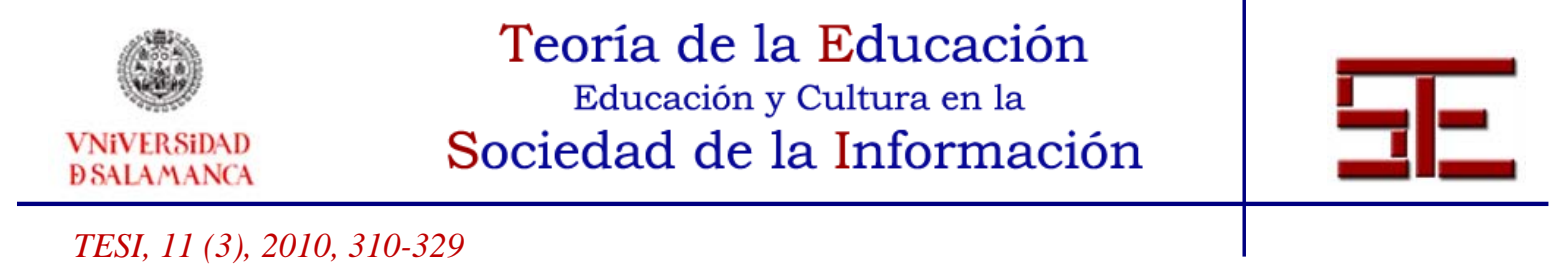

- Terminología. El lenguaje que utiliza el instructor para las explicaciones durante el taller es el hablado en el contexto del tema central. Ejemplo: En el taller de Fórmula 1 (escudería, circuito, alerón delantero, alerón trasero, etc.).

- Actividades extras. Comprende videos, lecturas o juegos que enriquezcan su aprendizaje.

\section{7.- RESULTADOS CONSEGUIDOS}

Aunque no podemos generalizar sobre las competencias conseguidas por cada participante, podemos aportar lo siguiente:

- Creatividad. Los participantes liberan su capacidad creativa al ofrecerles espacios para que imaginen, creen y realicen sus propias construcciones al permitirles enriquecer su trabajo o actividad con sus ideas y motivaciones personales.

- Autoestima. Hemos observado como la timidez inicial de algunos participantes fue disminuyendo a medida que transcurrían las sesiones, inclusive, de un taller a otro han pasado de ser seguidores a liderar sus grupos de trabajo. La confianza en sí mismos aumenta al descubrir que tienen el poder de crear objetos (robots) lo que al inicio les parecía "demasiado difícil".

- Concentración y disciplina. Se requiere aprender a perseverar cuando las cosas vayan mal para encontrar la manera de solucionar el problema, en lugar de ceder a la frustración. Y para algunos de estos participantes ha significado una victoria al ver su robot terminado.

- Trabajo en equipo. Los participantes tienen la libertad para agruparse según sus preferencias y son ellos quienes deciden las funciones que cada miembro del equipo realizará en cada sesión. El objetivo que los une hace que colaboren. Así, los que tienen mayor experiencia suelen tomar el control, pero todos participan en el proyecto.

Por último, otro aspecto digno de mención es la libertad de cometer errores. El error es una fuente de aprendizaje que puede usarse para mejorar nuestra comprensión de los problemas. Darle la mayor libertad en la toma de decisiones a cada participante, donde el instructor es un facilitador que le muestra alternativas en función de las soluciones propuestas por ellos, supone aprender a partir de los errores que ellos mismos tienen que corregir.

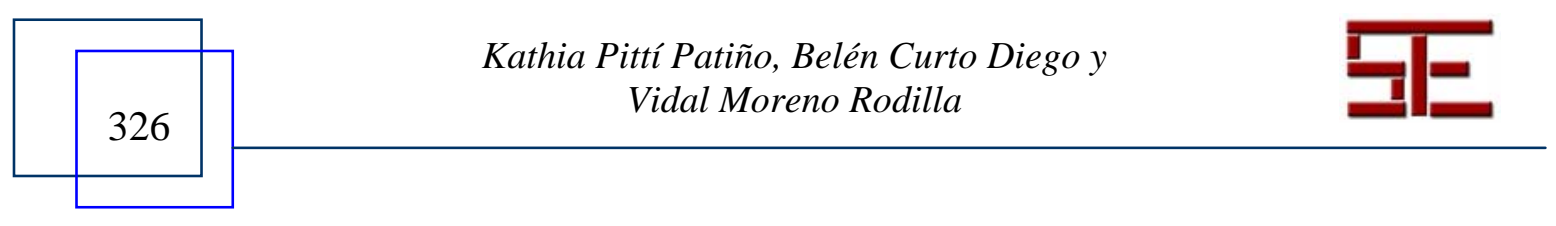




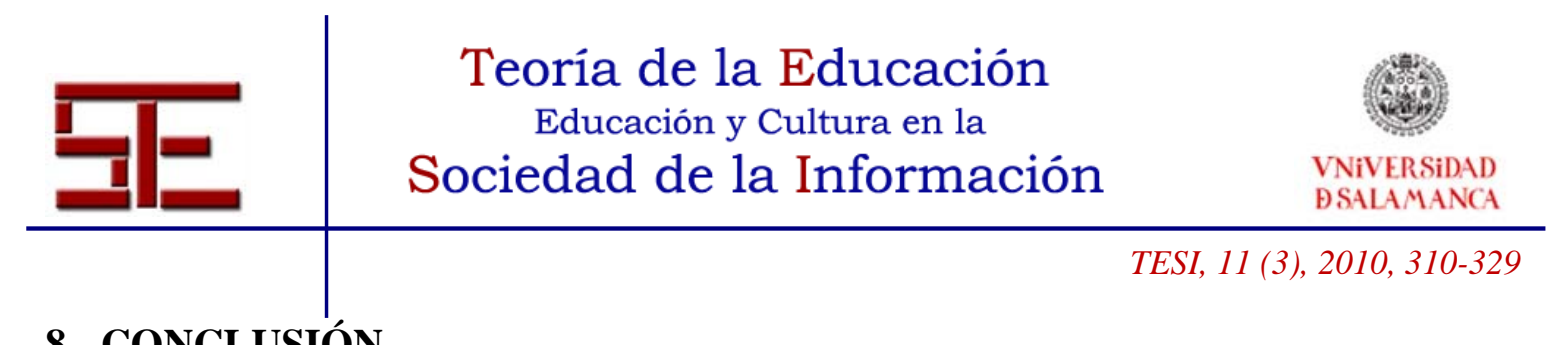

\section{8.- CONCLUSIÓN}

En este artículo se ha presentado la metodología de los talleres $N X T$, impartidos como actividades extraescolares en el CITA, cuyo objetivo es acercar la tecnología digital, específicamente, la robótica al público.

En términos construccionistas, los talleres NXT serían "micromundos" que incorporan la tecnología LEGO Mindstorms NXT como "objeto para pensar" permitiendo la construcción de robots que son transformados en "entidades públicas" por los aprendices durante todo el proceso y aún más, en la competición o exhibición final ante sus familiares y amigos.

Los resultados conseguidos se centran en el aumento de la creatividad y la autoestima, el logro de la concentración y la disciplina, y la colaboración a partir del trabajo en equipo.

El reto actual de la robótica educativa para la mayoría de los países, es pasar de ser una actividad extraescolar a integrarla como un recurso didáctico dentro del currículo escolar de forma permanente, no sólo en las asignaturas tecnológicas sino en aquellas donde pueda servir como apoyo para mejorar los procesos de enseñanza y aprendizaje; además de fomentar el desarrollo de las habilidades que son tan solicitadas en este nuevo milenio.

Más aún, debemos aprovechar las posibilidades educativas y sociales de Internet, creando comunidades de aprendizaje, que son necesarias para brindar un soporte a todos los interesados por conocer el potencial de la robótica educativa.

En definitiva, la robótica educativa ofrece un campo fértil para la investigación pedagógica. Está en nuestras manos aprovechar su utilización óptima con el fin de mejorar la práctica docente y profundizar en el conocimiento teórico y práctico acerca de la naturaleza y el impacto de esta tecnología sobre educación.

\section{9.- REFERENCIAS}

Acuña, A. (2007). La robótica educativa: un motor para la innovación. [Fecha de consulta: 10/08/2009] de http://www.fod.ac.cr/robotica/descargas/roboteca/articulos/2007/roboticamotor_i nnova_articulo.pdf .

Badilla, E. y Chacón, A. (2004). Construccionismo: objetos para pensar, entidades públicas y micromundos. Revista Actualidades Investigativas en Educación, (vol 4), Número 1. [Fecha de consulta: 12/08/2009] de

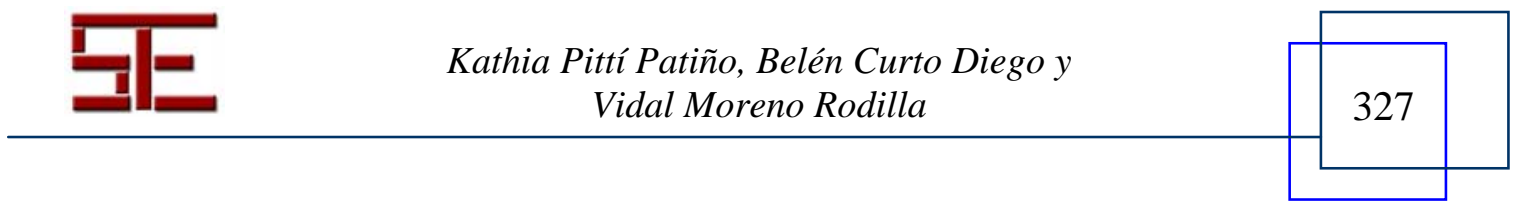




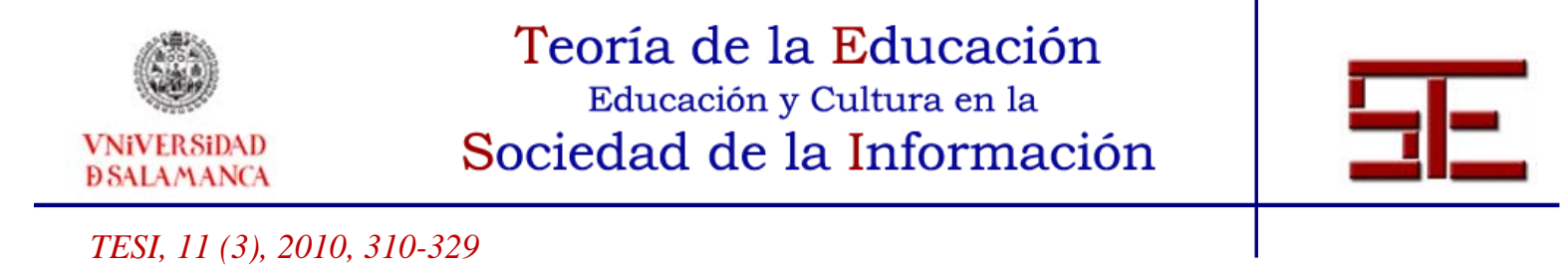

$<$ http://revista.inie.ucr.ac.cr/articulos/1-2004/archivos/construccionismo.pdf > .

Díaz, E., Manzano, J., Esperabe, I., Martín, J.A., Fernández, R., Mateos, J., Gualda, D., De Santiago, L. (2006). Introducción al diseño de microrobots móviles. [Fecha de consulta: 14/07/2009] de http://www.depeca.uah.es/docencia/LibreEleccion/IDMRM/trabajos0607/Robots LegoMindstorms.pdf.

Fundación Omar Dengo. (2006). Educación y tecnologías digitales. Cómo valorar su impacto social y sus contribuciones a la equidad. [Fecha de consulta: 03/11/2009] de < http://www.fod.ac.cr/idrc/contenidos/cap_1/cap_1-01a.htm >.

Fundación Omar Dengo. (2007). Robótica: espacios creativos para el desarrollo de habilidades en diseño para niños, niñas y jóvenes en América Latina. [Fecha de consulta: 13/07/2009] de http://www.programafrida.net/docs/informes/b66_robotica.pdf.

Gardner, H. (2005). Las cinco mentes del futuro. Barcelona: Paidós.

Goh, H. y Aris, B. (2007). Using robotics in education: lessons learned and Learning experiences. [Fecha de consulta: 25/08/2009] de http://eprints.utm.my/6015/1/149-henry.pdf.

LEGO Educacion. (2008). Fundamentación pedagógica: Proyecto Lego Zoom Argentina. [Fecha de consulta: 20/04/2009] de http://www.legoeducation.com.ar/home/fundamentacion.pdf.

Méndez, Z. (1995). Aprendizaje y cognición. San José (Costa Rica): EUNED.

Morin, E. (1999). Los siete saberes necesarios para la educación del futuro. [Fecha de consulta: 17/09/2009] de $<$ http://unesdoc.unesco.org/images/0011/001177/117740so.pdf $>$.

Papert, S. (1981). Desafío a la mente. Computadoras y educación. Buenos Aires: Ediciones Galápago.

Papert, S. y Harel, I. (1991). Situar el construccionismo. [Fecha de consulta: 10/08/2009] de http://www.incae.edu/ES/clacds/nuestros-proyectos/naciones-digitales/ construyendo-escenarios-para-el-desarrollo/pdfs/situar-el-construccionismo.pdf.

Papert, S. (1995). La máquina de los niños. Replantearse la educación en la era de los ordenadores. Barcelona: Paidós.

Papert, S. (s.f.). ¿Qué es Logo? ¿Quién lo necesita? [Fecha de consulta: 02/07/2009] de http://www.eduteka.org/modulos.php?catx=9\&idSubX=288.

Sánchez, M. (2002). Ambientes de aprendizaje con robótica pedagógica. [Fecha de consulta: 20/09/2008] de http://www.ribiecol.org/sietes/ini/ini/nac/p015.pdf.

Stager, G. (s.f.). En Pro de los computadores. [Fecha de consulta: 02/07/2009] de $<$ http://www.eduteka.org/imprimible.php?num=205\&catx=9>.

Reggini, H. (2005). Las computadoras deben considerarse como un medio expresivo para la creación: esa fue la esencia de Logo. [Fecha de consulta: 25/06/2009] de http://portal.educ.ar/noticias/entrevistas/horacio-c-reggini-las-computad.php.

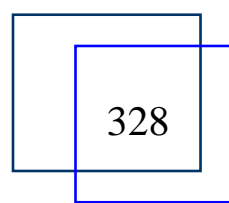

Kathia Pittí Patiño, Belén Curto Diego y Vidal Moreno Rodilla 


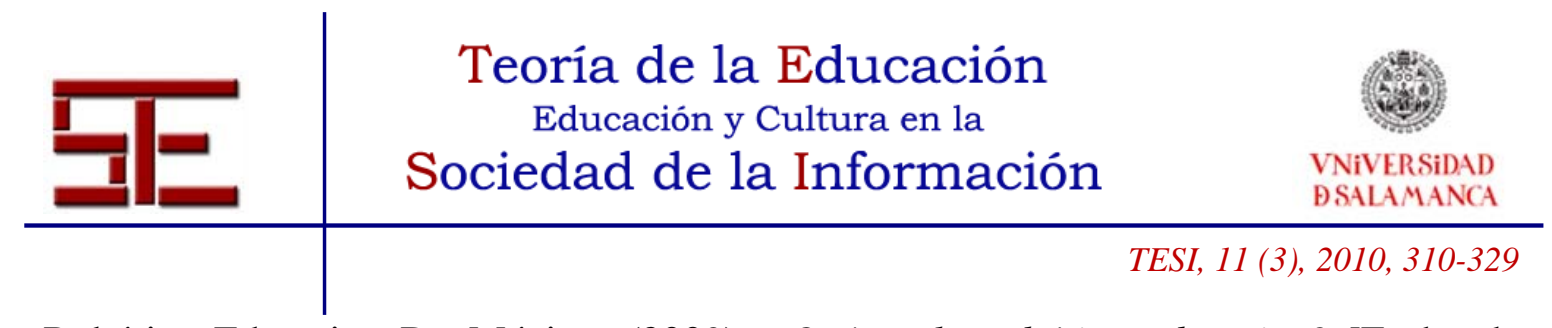

Robótica Educativa De México. (2009). ¿Qué es la robótica educativa? [Fecha de consulta: 08/08/2009] de http://roboticaeducativa.com.mx/blog/?page_id=13.

Ruiz-Velasco, E. (2007). Educatrónica: innovación en el aprendizaje de las ciencias y la tecnología. Buenos Aires: Editorial Díaz de Santos, S.A.

\section{Notas:}

[ $\left.{ }^{1}\right]$ Constructivismo de Piaget: corriente psicológica aplicada al ámbito educativo que explica la construcción del conocimiento como debido a las propias fuerzas del sujeto.

[2] "LOGO es el nombre de una filosofía de la educación dentro de una creciente familia de lenguajes de computadora que la acompaña. [...] LOGO es un lenguaje interpretativo. Esto significa que puede utilizarse en forma interactiva" (Papert, 1981, 246).

$\left[{ }^{3}\right]$ Mindstorms (Tormenta de ideas, en español) proviene del título del libro de Seymour Papert, llamado "Mindstorms: Children, Computers, and Powerful Ideas". La primera versión del robot LEGO Mindstorms, fue realizada en 1998, se llevó al mercado como el "Robotic Invention System" (RIS) y llegó a ser popular entre educadores y fanáticos, especialistas en robótica. La nueva versión, el NXT LEGO Mindstorms, es un conjunto de robótica programable realizado por LEGO en julio de 2006. Este reemplaza a la primera generación LEGO Mindstorms RCX. El robot Mindstorms NXT fue ideado en secreto con la ayuda de 100 desarrolladores.

$\left[{ }^{4}\right]$ La trandisciplinariedad, se refiere a lo que está al mismo tiempo entre, a través de, y más allá de las disciplinas. Su finalidad es la comprensión del mundo y la articulación de saberes.

Para citar el presente artículo puede utilizar la siguiente referencia:

Pittí Patiño, K., Curto Diego, B. y Moreno Rodilla, V.: (2010). "Experiencias construccionistas con robótica educativa en el centro internacional de tecnologías avanzadas”. En De Pablos Pons, J. (Coord.) Buenas prácticas de enseñanza con TIC [monográfico en línea]. Revista Electrónica Teoría de la Educación: Educación y Cultura en la Sociedad de la Información. Vol. 11, n 1 . Universidad de Salamanca, pp. 310-329. [Fecha de consulta: $\mathrm{dd} / \mathrm{mm} / \mathrm{aaaa}$.

http://revistatesi.usal.es/ revistas_trabajo/index.php/revistatesi/article/view/6294/6307

ISSN: $1138-9737$

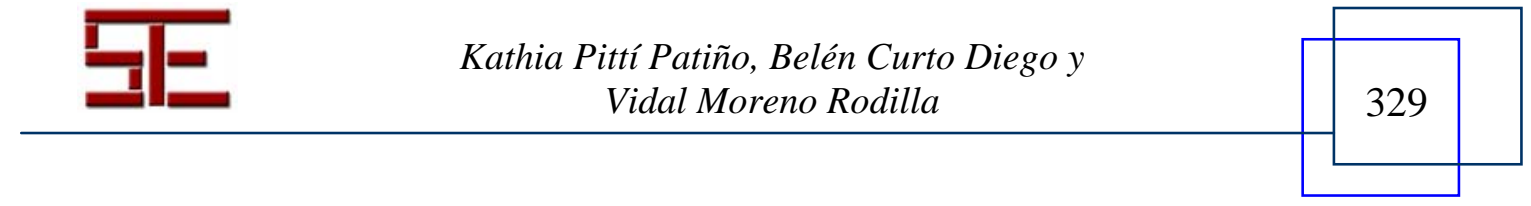

